\title{
Assessement of Managers Satisfaction regarding the HR Function in developing countries through a quantitative research method: The Moroccan context
}

\author{
Asmaa Elmortda ${ }^{1}$, Chams-Eddoha Mokhlis ${ }^{2}$, Ahmed Mokhlis ${ }^{1}$, Said Elfezazi ${ }^{1}$ \\ ${ }^{1}$ Laboratoire Process Signaux Système Industriel et Informatique (LAPSSII) ; Cadi AyadUniversity, Marrakesh, Morocco \\ ${ }^{2}$ Ecole Nationale de Commerce et de Management, Laboratory of Scientific Engineering of Organizations ; Hassan II University, \\ Casablanca, Morroco \\ asmaa.elmortada@gmail.com
}

\section{Article Info}

Received Jan 4, 2019

\section{Keyword:}

Human resources management Industrial companies

Morocco

Job satisfaction

Performance of HR function

\begin{abstract}
This paper presents a practice-oriented study that aims to reveal challenges faced by HR managers within developing countries through studying the Moroccan context. Indeed, we conducted a quantitative inquiry that evaluates the HR function performance based on Ulrich model. This study revealed the existence of several difficulties in terms of implementing a suitable HR function within industrial companies. The reliability of the inquiry was proven by calculating Cronbach Alphas. This research has important implications for HR professionals and strategic leaders that are especially interested in developing countries which will account for nearly $60 \%$ of global GDP in 2030, according to new estimates (OECD, 2018).
\end{abstract}

\section{CorrespondingAuthor:}

Asmaa ELMORTADA,

Laboratoire Process Signaux Système Industriel et Informatique (LAPSSII),

Cadi Ayad University,

549, Av.AbdelkarimElkhattabi, Guéliz Marrakesh, Morocco,

Email: asmaa.elmortada@gmail.com

\section{Introduction}

The strategic importance of human capital for competitiveness and development of organizations is widely recognized in the management literature [1]. These researchers have shown convincingly that the real challenge for businesses is to know how to manage their human and intellectual capital.This challenge reveals more importance for developing countries because it puts them in the need to structure the human resource function (HR function) within their companies while conferring the economic and managerial changes that affect their competitiveness. This structuration is also necessary because developing countries will account for nearly $60 \%$ of global GDP in 2030, according to new estimates [2].

In relation to this, our research is a practice-oriented study that aims to reveal challenges faced by HR managers within developing countries through studying the Moroccan context. Indeed, we conducted a quantitative inquiry that aims to evaluate HR function performance based on Ulrich model. This study revealed the existence of several difficulties in terms of implementing a suitable HR function within industrial companies. 


\section{Literature review}

\subsection{HR function' performance and managers' satisfaction}

Humanresource management has been, sinceitsappearance, a fascinatingfield of study. The amount of publishedwritings, on all its dimensions, revealswell the interestit has made on researchers and practitioners. Its first appearance as a simple "personnel administration" has been stimulated by the social change resultingfrom the IndustrialRevolutionduring the 19th century. It isonlysince 1970 that the HR function has ceased to beakin to a purely administrative approach of humanresources, and started to move toward HRM issues. It is at this time thatit has begantreating the workforce as a specificassetconstituting a strategic variable for the companydevelopment, instead of perceivingit as a costthatshouldbeminimized [3].

Several studies among employees were then conducted through literature.They were not limited only to the employees' attitude, but they also treated its directors and managers.

Based on the "internal customer" concept which was developed by Berry [4], managers and decision-makers were also considered as internal customers that the company should satisfy to ensure their ability to provide better service [5], particularly that the company performance sought to ensure the employees' satisfaction before it is reflected on the economic performance measures.

As part of this vision, several researchers have been interested in the satisfaction of decision-makers regarding management control. Laitinen [6], for example, stated that the quality of management control should be closely linked to the managers satisfaction regarding the proposed system. Thus, managers' satisfaction in terms of information needs influence positively the appropriateness of their decisions.

MarianelaFornerino [7] as well, proposed to integrate the satisfaction of non-opportunistic managers as new variable in the management control. Thus, they suggest some levers to maximize managers and employees satisfaction, which will influence positively the performance of the entire organization. "These levers have two dimensions: a technical dimension and a dimension of accompaniment; the first seems to be more decisive" [7]

At the same order of ideas, Trépé\& al [8] conducted a survey by nearly 17 directors in order to evaluate the performance of the HR function from a practitioners' perspective. As part of this study, they cited several criteria for evaluating the performance of the HR function such as effectiveness and efficiency of recruitment process, staff training, social relationships, collaborators loyalty and career management, mastery of payroll management, or the HRD's ability to be an administrative expert in addition to issues related to manufacturing.... Therefore, they assume more results namely that some "HR function tasks remain difficult to quantify" and that "despite the presence of organizations' HRD surveyed in the Management Committees or Executive Committee, the contribution of HR function in developing organization strategy doesn't clearly constitute a leaders' expectation" [8].

By its side, EUPAN (European Union Public Administrations Network) conducted a survey by 306 directors and HR managers of State administration within 26 European countries. The purpose of this study was to compare the performance of the HR function in order to facilitate sharing knowledge and experiences between the participating countries in this survey. Among the issues revealed by this study, we point out staff loyalty, including those with specific profiles (ex. senior executives, experts) through the "valuating skills, perspectives... and clarifying the career path, working conditions, management system and the organization dynamism..." [9].These HR practices come in perfect harmony with those revealed by Farnham [10]. He stated, moreover, that "evaluating the effectiveness of these HR activities allows an assessment of how well they are working in practice".

Hence, evaluating the HR function' performance from the perspective of HR managers and practitioners (as being responsibles for implementing HRM practices) constitutes the first step towards setting good HRM within countries.

\subsection{HRM in the Moroccan context}

In Morocco, human resource management (HRM); in its modern form; is a recent theme that has been influenced by political and economic facts relatively extrinsic to HRM. It has evolved through three stages [11]:

During the colonial period (1912-1956) many peasants fled their agricultural lands and settled in larger cities. This massive exodus yielded an abundant workforce from which the colonial economy took advantage because of the cheap labour. Hence the personal management was characterized by a lack of legislation because of the opposition of the French employers- and a continuation of management according to the target 
population: native workers or Europeans. Indeed, employers exercised strict control over Moroccan workers and bounded them by tough rules while European workers benefited from better labour rules and more decent work conditions.

By obtaining the independence in 1956, the Moroccan unionism, inspired by the economic and political events that marked its appearance, has contributed to the structuring of HRM practices within Moroccan territory enterprises. Within private companies that are benefiting from near-monopoly situation, trade unions promoted personnel administration, the emergence of social services for employees (health insurance, pensions, holidays...), they leaded also to the birth of the culture of bargaining and social dialogue. On the other side, trade unionism has also played a role in determining the introduction of legal constraints (minimum wage, employment contract, social security contributions, health and safety ...) in some major groups of family management that were strongly influenced by the colonial phase, and adopted the same strategic aspects of managing this workforce through the systematic rejection of all power-cons unions...

The political and the economic change experienced by Morocco since the 90s years had a broad impact on HRM. This influence was introduced by the creation of the free exchange zone with the European Union in order to make Morocco an attractive platform for foreign relocation. This affected HRM and promoted the launch of a vast project of updating the social relations within the Moroccan company. It thus resulted in two cases: multinationals firms aiming to "globalize" in order to harmonize their management practices, and businesses affected by the competition that are found forced to change their HRM by focusing more on the human factor.

Based on our experiences and observations with respect to the Moroccan companies, we believe that the effect of the change known during the 90s cannot be generalized to all types of businesses, especially in the presence of studies confirming this, namely Baayoud and Zouanat [11] were interested to give a certain characterization of Moroccan companies in terms of HRM in light of political and economic changes that have been historically known by Morocco. They confirmed the existence of a large difference between organized and unorganized structures in terms of HRM structuring. In our opinion, given that historically speaking multinational companies have been the most supplied to seek globalization; we assume that the company's size is a determining factor for the performance of the HR function.

Recently management control has becoming constituting an important component in organizational performance. In this context, Labyad [12], Director of a consulting firm, has collected important observations regarding the management control within Moroccan firms. He says as well as:

Generally, the implementation of management control systems in Moroccan enterprises remains very limited because of reasons related to the deficit of both the managerial culture and the information on the contributions of such function.

In this perspective, it was revealed that the weaknesses identified are spreading to all management systems including the Moroccan public organizations and firms that are starting to implement governance principles [13]. These institutions still in the first phase of integrating management systems through the "integrated management" [14; 15].

In a broader sense, El Yousfi [16], Kessab [17], Matmati [18], Oulahyane [19] and Zouidi [20] were more interested in management control as a tool promoting the performance of institutions. In this context, one of the results gotten by Kessab [17]is that: "This control is more oriented to the administrative budget control than to management, and [...] accepted by leaders of public companies who are often former senior officials of the administration, influenced by a purely administrative concept of management control”. Kessab [17].

\section{Study: evaluation of hr function based on ulrich model}

\subsection{Methodology}

This study aims to evaluate the HR function performance within Moroccan industrial companies through a quantitative research method based on the administration of a survey questionnaire for all the participants. The questionnaire was conceived based on Ulrich model [21], which used in assessing the HR function performancebsedon four roles: The role of the strategic partner; the role of change agent; the role of the administrative expert and the role of champion of employees. In this method, we operationalize concepts in the form of measurable variables that we evaluate by using statistical analysis tools based on mathematical calculations. Therefore, the use of measurement indicators reduces subjectivity, andfacilitates the analysis and interpretation of the results [22]. The reliability of measurements was proven by calculating Cronbach Alphas. 


\subsection{Sample and procedure}

In order to carry out this study we collected contact details of senior managers from different sources: Chamber of Trade and Industry, Unions Centers, managers' associations, personal contacts....

We prepared two versions of questionnaires: a web-based survey and a Word file questionnaire. The respondant is invited to choose the form he or she is confortable with. We also sent a cover letter to the participants' email addresses in which we highlited the aims of the inquiry and we ensured the confidentiality of the information that the respondant will diliver. The confidentiality is also garanted by using the anonymous wab-based survey.

As per our inquiry has interest to managers of industrial companies, the participant job position and the representation of a variety of industrial sectors was the main criterias for respondants selection. We hence chose the sample through a non-probabilistic method.

\subsection{Participants}

109 managers of different sized companies participated in our inquiry:20.18\% of these firms are subsidiaries of multinational companies, 22.94\% (25) are very large companies (over than 1000 employees), 21.10\% (23 firms) are large businesses (500-999 employees), 18.35\% (20) are medium-sized (50-499 employees), 11.93\% (13) are small enterprises (10-49 employees), and 5.50\% (6) are very small businesses (1-10 employees).

$24.8 \%$ of the firms operate in food industry, $19.3 \%$ in construction, $11 \%$ in automative industry, $11 \%$ in textile industry while $8.3 \%$ are mining or producing energy $(9.2 \%) .14 .7 \%$ of these companies manufacturatehealth products, cosmetics, packaging or produce handicrafts.

Seventy seven participants (70.6\%) are men; the average age was 39.40 years old, with an average experience of 15.71 years. Four participants $(3.67 \%)$ are $\mathrm{PhD}$ graduated. Sixty three respondents $(57.8 \%)$ have followed Engineering studies, MBA, or Master's Degree training, facing $20(18.35 \%)$ participants that followed a Mastery training (4 years after the baccalaureate in the old higher education system inMorocco). Thirteen interviewees (11.93\%) had a Bachelor degree, while 3 of them (2.75\%) studied only 2 years after high school. 6 persons $(5.5 \%)$ have benefited from a qualifying training.

\subsection{Measures}

Measurement was performed based on a questionnaire model that we inspired from established scales through literature. We proposed questions based on the aspects covered, as we formulated them in the light of recommendations of experienced people in the field of HRM.

Indeed, our evaluation of the HR function is based on the model of Ulrich [23] which assigns four roles to the HR function: the administrative expert, the employees' champion, the change agent, and the strategic partner. This model has been used in several studies [24; 25].

Based on this model, we asseignedvaraibles to each role. The assessement of the HR function role is hence done through meseauring these variables. Consequently, in our study, we designated the variable "Documentation" $(\alpha=0.862)$ to evaluate the administrative expert role $(\alpha=0.844)$ while employee incentive isintended to assess the role of employee champion. On the other side, communication assesses the change agent role (0.853), and the participation in decision making evaluate strategic partner role $(\alpha=0.957)$. Each chosen variable was measured through different relevant sub-variables [26].

In this context, we used global, dichotomous and Likert scales according to the sub-variable to measure.

\subsection{Control variables}

Since our questionnaire contains an identification section of the interviewee (sex, age, educational level...); we considered the items this section as control variables. This is not only possible because such data is often used in HRM studies [27], but this still valid since these dimensions can affect relationships that we are interested in as demonstrated through literature. Other variables related to the identification of the company can also be used; if needed; as control variables. Among these variables we can mention company size, and its activity sector.

\subsection{Analysis tools}

We used the SPSS software to analyze the collected data through proceeding to various mathematical tests such as the flat sorting, chi-square tests, ANOVA analysis, cross tabulations... thechoice of mathematical tests is justified by the literature of data analysis within social sciences [28]. 


\section{Findings}

Since we assessed the HR function based on Ulrich model, our finding are as follows:

Table 1: Summary table of some calculated statistical tests

\begin{tabular}{|c|c|c|c|c|}
\hline $\begin{array}{ll}\text { relationship } & \text { Test Tested } \\
\end{array}$ & Correlation test (r) & $\begin{array}{l}\text { Chi-square } \\
\qquad(\chi 2)\end{array}$ & $\mathbf{f}$ & $\mathbf{P}$ \\
\hline $\begin{array}{l}\text { Company size / Human resource function } \\
\text { structuring }\end{array}$ & ---- & 69.00 & 25 & $0.00 * *$ \\
\hline $\begin{array}{l}\text { Human resource function performance / } \\
\text { Administrative expert }\end{array}$ & 0.94 & --- & --- & $0.00 *$ \\
\hline $\begin{array}{l}\text { Human resource function performance / } \\
\text { Employees'champion }\end{array}$ & -0.72 & --- & --- & $0.47 *$ \\
\hline $\begin{array}{l}\text { Human resource function performance / } \\
\text { Change agent }\end{array}$ & 0.45 & ---- & --- & $0.00 *$ \\
\hline $\begin{array}{l}\text { Human resource function performance / } \\
\text { Strategic partner }\end{array}$ & 0.74 & --- & --- & $0.00 *$ \\
\hline
\end{tabular}

$* \mathbf{p}<0.05 ; * * \mathbf{p}<0.001$

\section{The administrative expert role}

Based on the results of the inquiry that we conducted, firms give more interest to documenting recruitment and remuneration, they focus then on documenting internal mobility, employees departures, trainings processes and lastly social relations.

In line with the assessement of the administrative expert role, 80 participants confirmed that the firms they belong to implement clear labor procedures that the employees highly respect ( $80 \%$ of the employees respect the regumation).

On the other hand, participating companies use indicators related toabsenteeism (71.6\%), seniority (66.1\%), effective $(64.2 \%)$, attendance $(42.2 \%)$, performance $(23.9 \%)$, wages assessement $(6.4 \%)$, turn-over $(6.4 \%)$ and outsourced missions $(7,3 \%)$.

Thus, analysis results mentioned in Table 1 have shown a strong correlation between HR function performance and the administrative expert role $(\mathrm{r}=0.941 ; \mathrm{p}=0.000)$. In other words, the more a company is large-sized, the more its administrative management contributes to the HR function performance.

\section{The employees' champion role}

Based on the results of this study, $16.5 \%$ of the firms provide facilities for the employees willing to pursuit their professional or academic studies.More than 53\% of the companies adopt anintegration system for new recruits through which they could benefit from the expience of the company previous employees.

On the other hand, $68.6 \%$ of the participating firms, encourage the creativity of their employees by asking them to propose innovative solutions to the faced labor problems, even if only $42,2 \%$ of these companies follow up the implementation of the suggested solutions.

On the other hand, we conducted a correlation analysis that results in: $r=-0.72 ; p=0.472$ (non-significant relationship). Thisshows that the contribution of employees' champion role into the HR function performance cannot be clearly judged. It, indeed, depend on the business type.

\section{The change agent role}

Communication was considered as a determinant of change agent role. The inquiry revealed the use of different communication modes simultaneously. Indeed, collaborators may talk to their top managers face to face easily $(81.7 \%)$, or by phone $(63,6 \%)$ while others should speak to their superioors first $(27,5 \%)$ or even make an official request before communicating with the top manager $(32,1 \%)$.

We also found a moderate relationship between the role of change agent and the HR fuction performance, but this relationship remain highly significant $(\mathrm{r}=0.450 ; \mathrm{p}=0.00)$. 


\section{The strategic partner role}

The strategic partner role has a strong and positive correlation with the HR function performance $(\mathrm{r}=0.745$; $\mathrm{p}<0.01)$. Among seventy two companies (66.1\%) adopting a HR function, 52 respondents $(47.7 \%)$ confirmed that the human resources directors participate in strategic decision-making. However the rate of participation remain different from one company to another: $44 \%$ of the managers often participate in making decisions while $8,3 \%$ are sometimes do.

The results show that few participants (18\%) have access to the information provided by management indicators.

While assessing the effectiveness of the HRM systems, it was revealed that only $30.15 \%$ of managers are satisfied regarding their firms management systems.

\section{Conclusion}

This quantitative study that we conducted among 109 managers working in companies of different sizes and activities based on Ulrich model whose reliability was proven by calculating Cronbach Alphas, results in the fact that the structuring of the HR function is a predisposing condition for its performance as it was proven in other contexts by Kehri and Bouzar [29] and Trépé et al [8].. Though, aspects of this performance remain debatable. In deed; measurement has shown that the performance of the HR function is more focusing on administrative issues than on the managerial ones due to the influence of corporate culture which remains closed in most cases. In such environment, it is not surprising to find that approximately only one third (34.17\%) of managers is satisfied regarding the effectiveness of management systems in their businesses. It constitutes a challenge as El Yousfi [6] states.

The constraints of competition and open economic strategies strongly contribute to the development of management practices adopted by multinationals or very large sized companies that are trying to give a socially responsible corporate image and seeking the harmonization between the HR function partners to improve management and efficiency of their systems. [29]. Large enterprises continue to face obstacles in managing their human resources as they are in a "fallback" position characterized by the desire to be opened up economically and continuity of management according to outdated practices inside of a culture known by the inflexibility to change. In this case, the solution remains in seeking the harmonization among the human resources in order to lead different chains to perform effectively [30].

\section{References}

[1] Bartlett, CA \&Ghoshal, S. (2002). Building competitive advantage through people, Sloan Management Review 43, 2, pp. 32-74.

[2] OECD: The Organization for Economic Co-operation and Development. (2018). http://www. oecd.org/development/pgd/economydeveloping countriessettoaccountfornearly60ofworldgdpby2030accor dingtonewestimates.htm. Viewed on 29 May 2018.

[3] Igalens, J.(1999). Satisfaction au travail. [auteur du livre] R Le Duff. Encyclopédie de la gestion et du management. Paris : Dalloz, 1999, pp. 1246-1247.

[4] Berry, L. (1981). The employee as customer ?. Journal of RetailingBanking 3 (March) : 33-40.

[5] Heskett, J.L., Jones, T., Loveman, G., Sasser, W. and Schlesinger, L. (1994). Putting the service profit chain to work. Harvard Business Review. 105-111

[6] Laitinen, E.K. (2004). Nonfinancial Factors as Predictors of Value Creation : Finnish Evidence. Review of Accounting and Finance 3(3) : 84-130.

[7] Godener A, RAY D. (2010). La satisfaction des managers vis-à-vis du contrôle de gestion et leur performance managériale. Comptabilité - Contrôle - Audit 2010/3 (Tome 16), p. 101-126. DOI 10.3917/cca.163.0101

[8] Trépé A, Aubert P, Bermond F, Carrère J.M, Delanoue M, Gouzi B (2010). Mémoire d'expertise : L'évaluation de la performance de la fonction $\mathrm{RH}$ : De la théorie à la pratique des $\mathrm{D}$. Viewed on rh.dauphine.fr/fileadmin/mediatheque /site/mba_rh/pdf/Travaux_anciens/Evalu ation de la performance de la fonction RH selon DG.pdf. 02/05/2015 at 14:48 pm (GMT). 
[9]Ernst\&Young (2008).Performance de la fonction ressources humaines:perspectives et approches opérationnelles.P 16.

[10] Farnham D. (2010). Resource Management in Context. 3rd edition, Published by the CIPD

[11] Baayoud, M. Zouanat, H, 'Evolution de la Fonction RH au Maroc', 2010, http://www.fmrh.org/publicationobse rvatoire /cat view/2-documents-publics/12/25?Limit $=5$ $\underline{\text { \&order }=\text { name } \& \text { dir }=\text { ASC }}$

[12] Labyad A. (2005). Contrôle de gestion: Une dynamique de création de valeur. L'Economiste. Edition $\mathrm{N}^{\circ}: 2058$ Le 06/07/2005. http://www.leconomiste.com/article/ controle-de-gestion-une-dynamique-decreation-de-valeurbrpar-abderrahim-labyad directeur-du- . Last consultation on 08/06/2016 at 23:04.

[13] Talbi, A. (2010). Contrôle financier et gouvernance des entreprises publiques au Maroc. (Workingpaper, presented at Rencontre MENA-OCDE sur la gouvernance d'entreprise, Direction des entreprises publiques et de la privatisation, Rabat, Morocco, 2010).

[14] Abouamama, R. (2007). Conception du BalancedScorecard, cas d'un Établissement Public: Office National des Pêches. http://www.abhatoo.net.ma/content/ download/ 11626/191820/version/1/file/BalancedScore Iscae.pdf. viewed on15 January 2017.

[15] Zerrouq, B. (2001). Étude comparative relative à la réforme du secteur public, ministère de l'Économie, des Finances, de la Privatisation et du Tourisme. Workingpaper no 67, Département de l'économie, des finances et de la privatisation, Direction de la politique économique générale, Rabat, Morocco, 2001.

[16] El Yousfi (2016). Les enjeux de la fonction RH. http://www.entreprendre.ma/Les-enjeux-de-la-fonctionRH_a6926.html. Last consultat-ion on 07/30/2016 at 22:56.

[17] Kessab J. (2009). Le CG dans le secteur publique. http://normes-ias-ifrs-au-maroc.over-blog.com/article29314624.html. Last consultat -ion on 08/08/2016 at 17:42.

[18] Matmati, M. (2016). La gestion des ressources humaines au Maghreb : Etat des lieux et perspectives. http://www.fmrh.org/etudesetprojets/projetagora/evolutionfonctionrhmaghreb/30maghrebetatslieuxperspectives? format=pdf . viewed on 30 July 2016.

[19] Oulahyane, A. (2016). Les enjeux de la fonction RH. http://www.entreprendre.ma/Les-enjeux-de-lafonction RH a6926.html. Viewed on 09 August 2016.

[19] Zouidi, L. (2013). La contribution du contrôle de gestion à l'amélioration de la performance dans le secteur public : le cas du Maroc. Unpublished dissertation, Université du Québec à Montréal, Montréal, Québec, Canada, 2013.

[20] Ulrich D.(1996). Human Resources Champions: The next agenda for adding value and delivering results, Boston, Harvard Business School Press, 281 p.

[21] Savall, H. Zardet, V., Recherche en sciences de gestion: Approche qualimétrique. Observer l'objetcomplexe. Economica (2004).

[22] Ulrich D. (1997). Measuring human resources: an overview of practice and a prescription for results. Human Resource Management, volume 36, n³, p. 303-320.

[23] Gilbert Patrick and Charpentier Marina (2004). Comment évaluer la performance RH ? Question universelle, réponses contingentes.

[24] Peretti J.M. (1998). La performance de la fonction ressources humaines : 1978- 1998. Economies et Sociétés, Sciences de gestion, $N^{\circ} 8-9$, p. 479-493.

[25] Gilbert P., Charpentier M., Layole G.(2007). Evaluation et pilotage de la performance RH. Donnez de l'intelligence à vos tableaux de bord. Revue Entreprise \& Personnel.

[26] Boselie, P., Dietz, G., \& Boon, C. (2005). Commonalities and contradictions in HRM and performance research. Human Resource Management Journal, 15 (3), 67-94.

[27] Costa R., MasuyStroobant G.(2013). Pratique l'analyse des données, Louvain la Neuve. 
[28] Kehri S., Bouzar C. (2010). Mémoire : La problématique de l'intégration stratégique des Ressources Humaines dans l'entreprise algérienne. http://www.ummto.dz/IMG/pdf/tout_mon_travail_Repare_.pdf. 02/05/2015 à 04:31

[29]Selcuk, S. (2013).Quality Management In Logistics Sector: Principles And Practice.Periodicals of engineering and natural sciences. Vol $1, \mathrm{~N}^{\circ} 1$.

[30]Sengupta P.P., Sinh M.,Dutta U.P. (2019).Economic and environmental performances in manufacturing industries: A comparative study. Periodicals of Engineering and Natural Sciences.ISSN 2303-4521 Vol. 7, No. 1, June 2019, pp.99-108.

\section{BIBLIOGRAPHY OF AUTHORS}
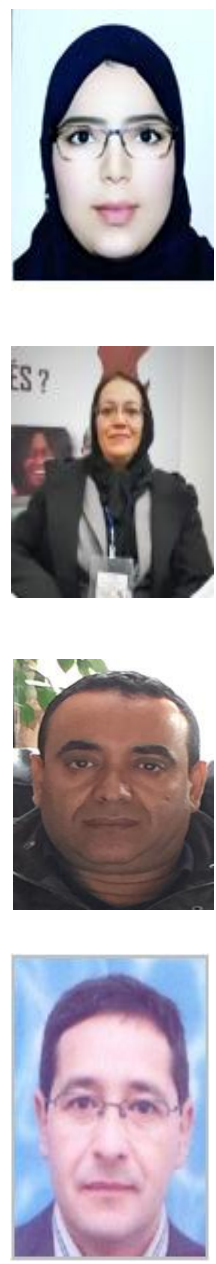

Asmaa ELMORTADA is a member of the Research Team in Industrial Engineering at Cadi Ayyad University, her research focuses on human resources management within industrial enterprises. HR function performance, knowledge management..Asmaa ELMORTADA is the corresponding author.

ChamsEddoha MOKHLIS is a professor researcher at the EcoleNationale de Commerce et de Management, that is one of the institutions ofHassan II University, Prof.Mokhlis's research interests in the area of human resources management and knowledge management.

Ahmed MOKHLIS is a professor researcher at the Higher School of Technology (EST UCA) and at National School of Applied Sciences of El jadida (ENSAJ_UCD). Prof.Mokhlis's research interests in the area of measuring the performance of industrial processes, and industrial indicators.

Said ELFEZAZI is a professor in the Department of Instrumental Techniques and Quality Control at the Higher School of Technology. He is currently responsible for the Research Team in Industrial Engineering at Cadi Ayyad University. Prof.Elfezazi's research interests in the performance of industrial processes, project management, industrial indicators, and logistic 